\title{
The NRF2 Activation and Antioxidative Response Are Not Impaired Overall during Hyperoxia-Induced Lung Epithelial Cell Death
}

\author{
Haranatha R. Potteti, ${ }^{1}$ Narsa M. Reddy, ${ }^{1}$ Tom K. Hei, ${ }^{2}$ \\ Dhananjaya V. Kalvakolanu, ${ }^{3}$ and Sekhar P. Reddy ${ }^{1}$ \\ ${ }^{1}$ Department of Pediatrics, College of Medicine, University of Illinois at Chicago, \\ Chicago, IL 60612, USA \\ ${ }^{2}$ Mailman School of Public Health, Columbia University, New York, NY 10032, USA \\ ${ }^{3}$ Department of Microbiology and Immunology and Greenebaum Cancer Center, \\ University of Maryland School of Medicine, Baltimore, MD 21201, USA
}

Correspondence should be addressed to Sekhar P. Reddy; sreddy03@uic.edu

Received 31 January 2013; Accepted 25 March 2013

Academic Editor: Hye-Youn Cho

Copyright (C) 2013 Haranatha R. Potteti et al. This is an open access article distributed under the Creative Commons Attribution License, which permits unrestricted use, distribution, and reproduction in any medium, provided the original work is properly cited.

Lung epithelial and endothelial cell death caused by pro-oxidant insults is a cardinal feature of acute lung injury/acute respiratory distress syndrome (ALI/ARDSs) patients. The NF-E2-related factor 2 (NRF2) activation in response to oxidant exposure is crucial to the induction of several antioxidative and cytoprotective enzymes that mitigate cellular stress. Since prolonged exposure to hyperoxia causes cell death, we hypothesized that chronic hyperoxia impairs NRF2 activation, resulting in cell death. To test this hypothesis, we exposed nonmalignant small airway epithelial cells (AECs) to acute (1-12 h) and chronic (36-48 h) hyperoxia and evaluated cell death, NRF2 nuclear accumulation and target gene expression, and NRF2 recruitment to the endogenous HMOX1 and NQO1 promoters. As expected, hyperoxia gradually induced death in AECs, noticeably and significantly by $36 \mathrm{~h} ; \sim 60 \%$ of cells were dead by $48 \mathrm{~h}$. However, we unexpectedly found increased expression levels of NRF2-regulated antioxidative genes and nuclear NRF2 in AECs exposed to chronic hyperoxia as compared to acute hyperoxia. Chromatin Immunoprecipitation (ChIP) assays revealed an increased recruitment of NRF2 to the endogenous HMOX1 and NQO1 promoters in AECs exposed to acute or chronic hyperoxia. Thus, our findings demonstrate that NRF2 activation and antioxidant gene expression are functional during hyperoxia-induced lung epithelial cell death and that chronic hyperoxia does not impair NRF2 signaling overall.

\section{Introduction}

The induction of antioxidant gene expression in lung-resident and infiltrated inflammatory cells in response to oxidative stress plays a significant role in pulmonary defense mechanisms $[1,2]$. However, disequilibrium between prooxidant load and antioxidant defenses, leading to redox imbalance, could potentially enhance tissue susceptibility to oxidative stress, thereby contributing to the lung pathogenesis of many acute and chronic airway diseases. These diseases include idiopathic pulmonary fibrosis, emphysema, bronchopulmonary dysplasia, acute lung injury (ALI)/acute respiratory distress syndrome (ARDS), and lung cancer [3-6]. Supplemental oxygen (hyperoxia) is used as therapy to treat ALI/ARDS patients. In mice, chronic exposure to hyperoxia results in endothelial and alveolar epithelial cell death accompanied by pulmonary edema and respiratory impairment; these pathologic features are similar to those observed in ALI/ARDS patients [7]. Thus, understanding the mechanisms by which hyperoxia contributes to lung 
pathogenesis is crucial to limiting the potentially harmful effects of oxygen toxicity in the clinical setting.

We have previously shown that NF-E2-related factor 2 (Nfe2l2, also known as Nrf2), a bZIP transcription factor, is crucial for the induction of several antioxidant and cytoprotective genes in response to various pro-oxidant stimuli, including hyperoxia $[8,9]$. Nrf2-deficient mice are more susceptible than wild-type mice to inflammatory and hyperpermeability responses to hyperoxic insult; this response has been generally attributed to a diminished or low expression level of several antioxidant enzymes (AOEs), including gene encoding NQO1, HMOX1, GCLC, GCLM, and GPXs [8, 9], which detoxify reactive oxygen species (ROS) and/or nitrogen (RNS) species. We have also shown that a loss of Nrf2 impairs the resolution of hyperoxia-induced acute lung injury and inflammation and also exacerbates bacterial infection in adult mice following hyperoxic insult [10].

One-day old Nrf2-deficient pups, when exposed to hyperoxia for $72 \mathrm{~h}$, develop greater levels of alveolar simplification (septal growth arrest) at the 4th day [11] and 14th day [12] than do Nrf2-sufficient pups. Nrf2 deficiency enhances cellular stress and susceptibility to oxidant-induced lung epithelial cell death [13], and its overexpression confers cellular protection against hyperoxia in lung epithelial cells [14] as well against proapoptotic stimuli in nonlung epithelial cells [15, 16]. These observations suggest an important role for the Nrf2-driven transcriptional response in mitigating cellular stress induced by prooxidants.

Since chronic exposure to hyperoxia causes the death of lung epithelial cells, despite the presence of NRF2, we hypothesized that dysfunctional NRF2 signaling may contribute to this cell death. To test this hypothesis, we have now analyzed the nature of NRF2 activation (nuclear accumulation) and recruitment to the antioxidant gene (HMOX1 and NQO1) promoters in human nonmalignant lung small airway epithelial cells during acute and chronic hyperoxia exposure. Here, we report that chronic hyperoxia does not impair NRF2 nuclear accumulation or antioxidant gene expression during the hyperoxia-induced death of lung epithelial cells.

\section{Materials and Methods}

2.1. Human Lung Epithelial Cell Culture and Hyperoxia Exposure. The human normal small airway epithelial cell line (hereafter referred to as AECs) was established by the ectopic expression of human telomerase reverse transcriptase (hTERT). Cells were grown in Dulbecco's Modified Eagle Medium with Ham's F12 nutrient mixture (DMEM/F12) in the presence of $10 \%$ FBS and antibiotics [17]. Cells were plated in equal number, grown to $70 \%-80 \%$ confluence and then exposed to hyperoxia in complete medium. For generating hyperoxic condition, cells were kept in modular incubator chamber (Billups-Rothenberg, Del Mar, CA) and filled with gas mixture containing $95 \% \mathrm{O}_{2}$ and $5 \% \mathrm{CO}_{2}$ and chambers placed in $37^{\circ} \mathrm{C}$ incubator. The chambers were refilled with the gas mixture every $12 \mathrm{~h}$. As room air control group, cells were placed in the regular cell culture incubator with room air and $5 \% \mathrm{CO}_{2}$ at $37^{\circ} \mathrm{C}$. Culture medium was changed every $24 \mathrm{~h}$ during the exposure period.

2.2. Gene Expression Analysis. Cells were exposed to either room air (RA) or hyperoxia $\left(95 \% \mathrm{O}_{2}\right.$ and $\left.5 \% \mathrm{CO}_{2}\right)$ for the indicated time periods. Total RNA was isolated using Trizol reagent (Gibco-BRL/Life Technologies, Grand Island, NY) and reverse transcribed using the qScript cDNA SuperMix (Quanta BioSciences, Gaithersburg, MD). Target gene expression was assessed by quantitative RT-PCR (qRT-PCR) using TaqMan gene expression assays (Applied Biosystems, Foster City, CA). For Immunoblot analyses, total protein was extracted in lysis buffer consisting of $20 \mathrm{mM}$ Tris $(\mathrm{pH}$ 7.5), 150 mM NaCl, 1 mM EDTA, 1 mM EGTA, 1\% Triton X$100,2.5 \mathrm{mM}$ sodium pyrophosphate, $1 \mathrm{mM} \mathrm{Na} 3 \mathrm{VO}_{4}, 5 \mathrm{mM}$ $\beta$-glycerophosphate, and $1 \mu \mathrm{g} / \mathrm{mL}$ leupeptin. Comparable amount of total protein $(\sim 40 \mu \mathrm{g})$ from each sample was separated on a $10 \%$ sodium dodecyl sulfate polyacrylamide gel electrophoresis (SDS-PAGE), and the membranes were probed with antibodies specific for NRF2 (Santa Cruz Biotech, Santa Cruz, CA), HMOX1 (Santa Cruz Biotech, Santa Cruz, CA), NQO1 (Abcam, Cambridge, UK), GCLC (kindly provided by Dr. Terrance Kavanagh, University of Washington, Seattle, WA). $\beta$-actin (Sigma, St. Louis, MO) antibody was used as the loading control. The blots were developed using an ECL kit (HyGlo, Denville Scientific Inc., Metuchen, NJ).

2.3. Cell Viability Assays. Cells in equal number were plated and exposed to hyperoxia as described above. Cell viability was quantified by CellTiter-Glo kit (Promega, Madison, WI) and MTT assay. LDH release was measured by CytoTox 96 NonRadioactive Cytotoxicity assay kit (Promega, Madison, WI). Viability and LDH release was calculated as a percentage of increase or decrease over their respective room air controls.

2.4. Chromatin Immunoprecipitation (ChIP) Assays. ChIP assays were performed using the EZ-ChIP assay kit (Millipore, Billerica, MA). Briefly, AECs were exposed to either room air or hyperoxia for indicated time points, crosslinked with formaldehyde, and chromatin fragmentation was carried out as detailed in the kit procedure. Diluted soluble chromatin solution was incubated with rabbit antiNRF2 (Santa Cruz Biotechnology, Santa Cruz, CA) for $18 \mathrm{~h}$ at $4^{\circ} \mathrm{C}$ with rotation. Nonimmune rabbit $\operatorname{IgG}$ was used as a negative control to determine the binding specificity. Following incubation with protein A/G agarose beads, the bound products were washed, and DNA was eluted. DNA was subjected to PCR with primers encompassing the functional antioxidant response elements (AREs) located upstream of transcriptional start site of HMOX1 (F: $5^{\prime}$-CCCTGCTGAGTAATCCTTTCCCGA-3' and R: $5^{\prime}$ ATGTCCCGACTCCAGACTCCA-3 ${ }^{\prime}$ ) and NQO1 (F: $5^{\prime}-\mathrm{G}$ TGGAAGTCGTCCCAAGAGA- $3^{\prime}$ and R: $5^{\prime}$-TGTCTCCCC AGGACTCTCTCAG- $3^{\prime}$ ) to determine the binding of NRF2 in ChIP assays. 


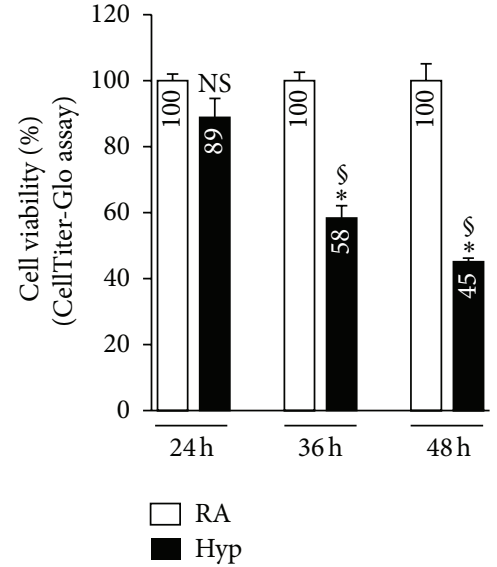

(a)

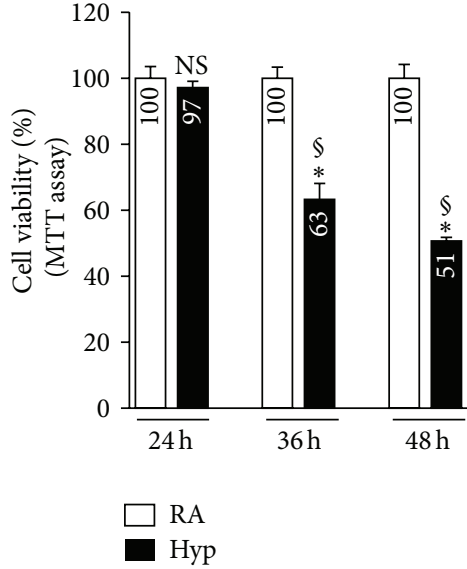

(b)

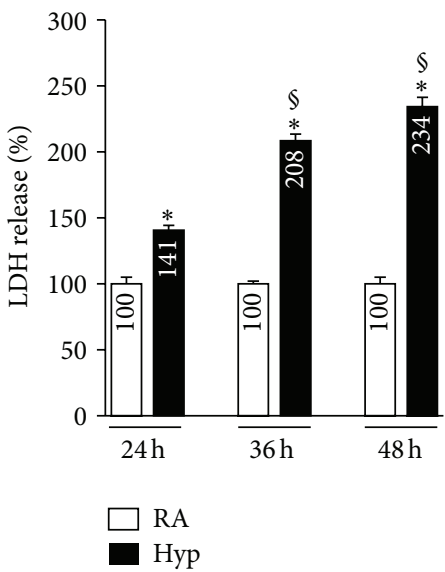

(c)

FIgURE 1: Hyperoxia induced cell death in AECs. Cells were exposed to hyperoxia (hyp) or room air (RA) for up to $48 \mathrm{~h}$, and cell viability was measured at the indicated time points. Cell viability assay was evaluated with CellTiter Glo Reagent (a), MTT reagent (b), and LDH release into the culture medium (c). Results are represented as the percent viability of cells (a and b) or LDH release (c) in comparison to their time matched RA control groups. The graph represents mean \pm SD of 4 independent experiments performed in triplicate. $P$ values are calculated using two-way ANOVA by Prism software. ${ }^{*} P \leq 0.05$, RA versus hyp; $\S: P \leq 0.05,24$ h hyp versus 36 h hyp or 36 hyp versus 48 h hyp.

2.5. Transfections and Reporter Gene Analyses. Cells were transfected with the NQO1 (NADPH: quinone oxidase reductase-1) promoter reporter (luciferase) construct [18] (kindly provided by Jeffrey Johnson, University of Wisconsin). To normalize transfection efficiency between wells, the cells were cotransfected with $5 \mathrm{ng}$ of the Renilla luciferase plasmid pRL-TK (Promega Corp., Madison, WI). At $24 \mathrm{~h}$ after transfection, cells were exposed to either room air or hyperoxia, and extracts were assayed for firefly and the Renilla luciferase activities using a dual luciferase kit (Promega Corp., Madison, WI). Firefly luciferase activity was normalized to that of Renilla.

2.6. Statistical Analyses. Data were expressed as the mean \pm SD $(n=3-9)$ as indicated in the legends. The significance between the exposures was calculated by one-way or two-way (for cell viability and LDH release) analysis of variance followed by the Bonferroni post hoc tests by GraphPad PRISM 4 Software. A $P$ value of $\leq 0.05$ is considered statistically significant. We also performed Student's $t$-test to confirm one-way analysis.

\section{Results}

Malignant human lung epithelial cells express higher levels of NRF2 than do nonmalignant lung epithelial cells mainly because of mutations in the inhibitor of NRF2, KEAP1, which is known to facilitate NRF2 degradation under basal conditions [19-21]. To overcome this problem and to determine whether chronic hyperoxia promotes lung epithelial cell death by suppressing the NRF2-mediated transcriptional response, we have utilized a nononcogenic human lung (small airway) epithelial cell line immortalized by telomerase [17]. To assess the effect of hyperoxia on airway epithelial cells (AECs), we subjected the cells to hyperoxia for 24 to
$48 \mathrm{~h}$ and measured cell viability by using CellTiter-Glo and MTT reagents; LDH release was evaluated by Cytotox. No significant difference in cell viability was observed between room air and hyperoxia during the first $24 \mathrm{~h}$ of exposure (Figure 1(a)). However, after $36 \mathrm{~h}$, hyperoxia had produced a significant decline $(\sim 42 \%)$ in cell viability (as determined by CellTiter-Glo), which fell to $\sim 55 \%$ at $48 \mathrm{~h}$. To verify this result, we evaluated cell viability using MTT assay (Figure 1(b)). Hyperoxia caused a significant decline ( $37 \%$ loss $)$ in cell viability after $36 \mathrm{~h}$, and the loss of viability increased $~ 49 \%$ at $48 \mathrm{~h}$; in contrast, hyperoxia exposure for $24 \mathrm{~h}$ had no significant effect on cell viability when compared to room air controls.

We also analyzed hyperoxia-induced cellular toxicity, as measured by $\mathrm{LDH}$ release into the culture medium. A significant increase in LDH release was detected in cells exposed to hyperoxia for $24 \mathrm{~h}$ (Figure 1(c)), when compared to their room air-exposed counterparts. However, the LDH released by the cells exposed to hyperoxia for $36 \mathrm{~h}$ to $48 \mathrm{~h}$ was markedly higher than the amount in the corresponding room air controls (Figure 1(c)). The discordance in results between the cell viability (Figures $1(\mathrm{a})$ and $1(\mathrm{~b})$ ) and LDH measurement (Figure 1(c)) at the $24 \mathrm{~h}$ time point may be related to the differences in the sensitivity of the assays.

To determine the impact of chronic hyperoxia on the regulation of the NRF2-dependent antioxidant transcriptional response, we subjected cells to either acute (1-12 h) or chronic (36-48 h) hyperoxia and determined the expression levels of HMOX1, GCLC, and NQO1 by qRT-PCR and immunoblot analysis. We selected these genes because they are upregulated by cellular stress and are putative transcriptional targets of NRF2 and because they are known to play key roles in cellular detoxification processes (reviewed in [22]). As anticipated, acute hyperoxia markedly stimulated GCLC (2.3fold) and NQO1 (2.7-fold) mRNA expression by as early as 

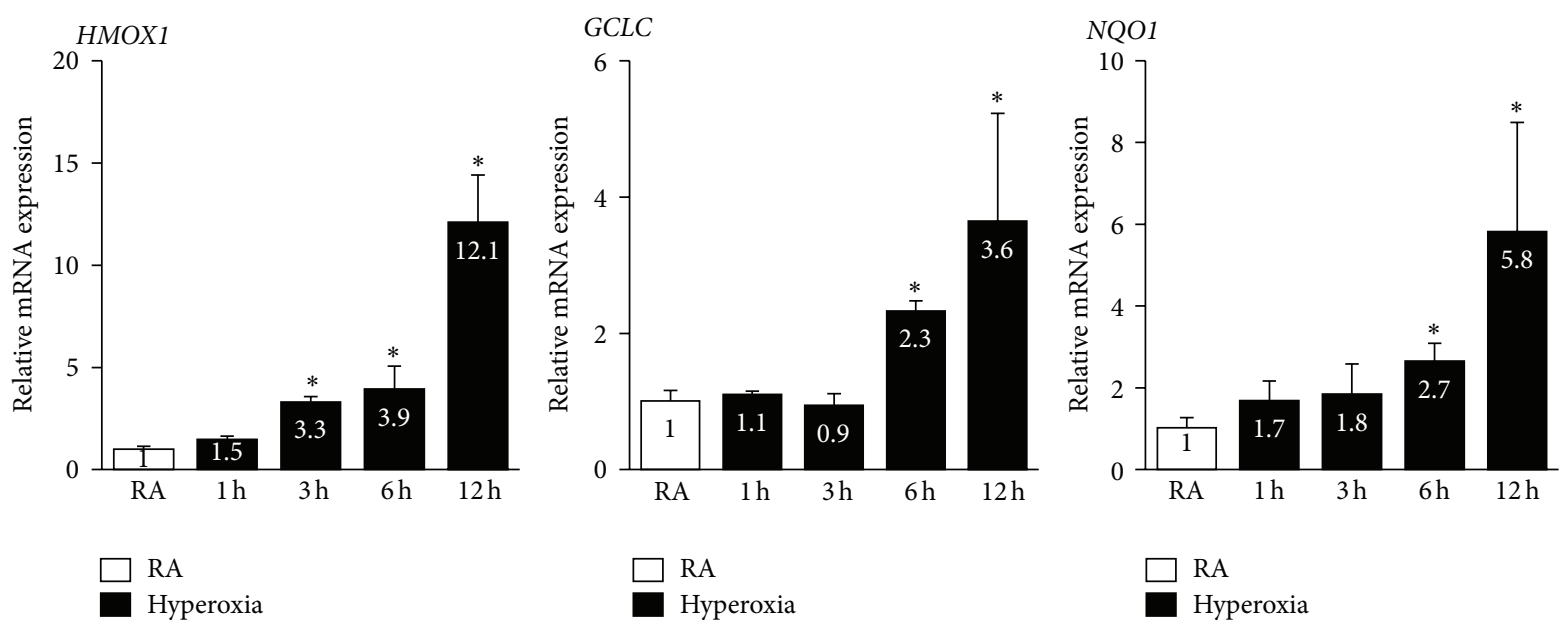

(a)
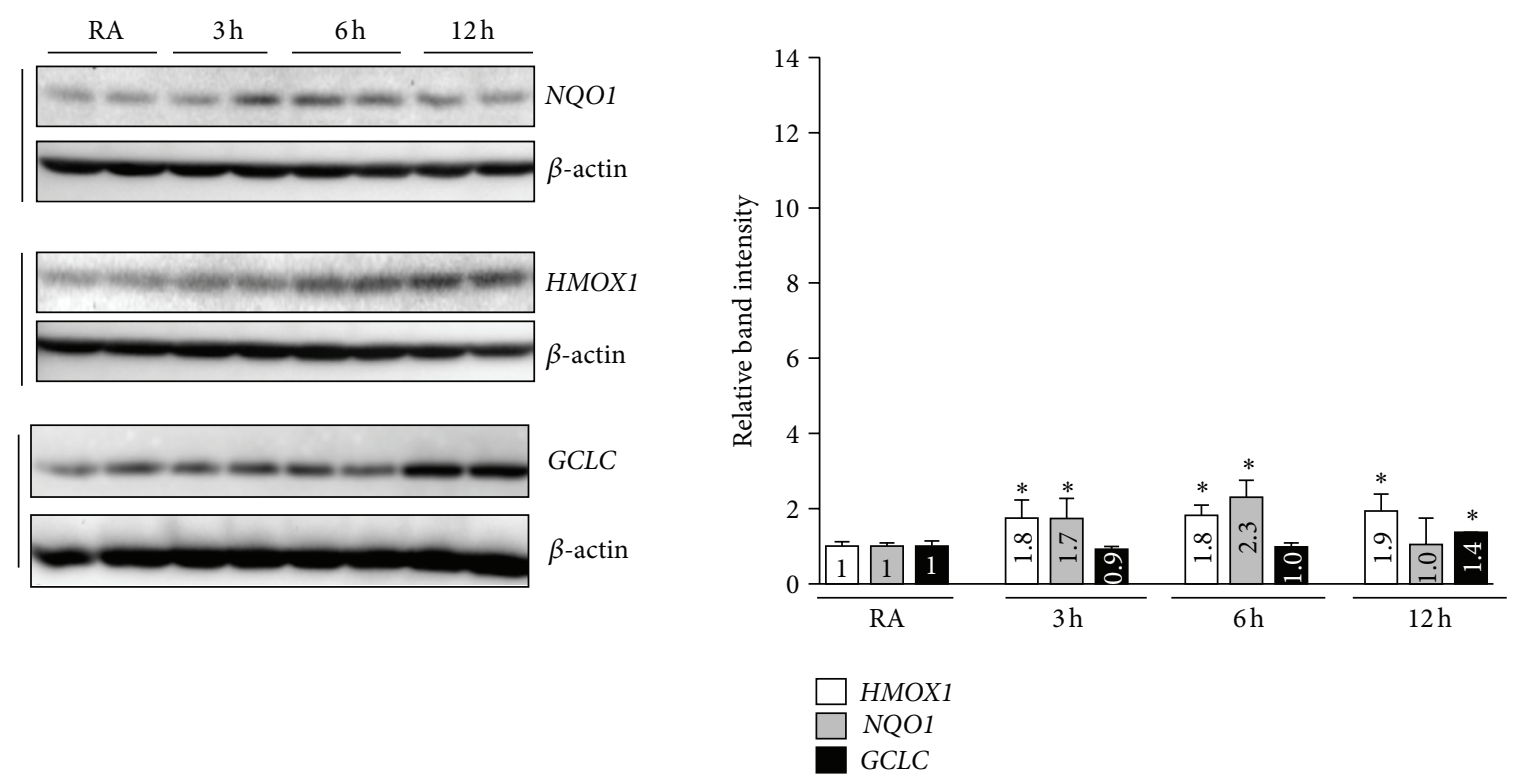

(b)

FIGURE 2: NRF2 target gene expression in AECs exposed to acute hyperoxia. Cells were exposed to either room air or hyperoxia for 1 to $12 \mathrm{~h}$ and then harvested at indicated time points for total RNA, and protein extraction. (a) cDNA was prepared from total RNA and the mRNA expression levels of HMOX1, GCLC and NQO1 were quantified using TaqMan assay probes. The values represent the mean \pm SD of three independent experiments $(n=3) .{ }^{*} \mathrm{P}<0.05 \mathrm{RA}$ versus hyperoxia. (b) A comparable amount of whole cell extracts $(\sim 40 \mu \mathrm{g})$ was separated on SDS-PAGE gel and immunoblotted with anti-HMOX1, anti-NQO1, or anti-GCLC antibodies. $\beta$-actin was used a as reference. Graph represents the relative band intensities of the HMOX1, NQO1, and GCLC of three independent experiments done in duplicate $(n=6)$. The band intensities were quantified using Image J software and normalized with their respective $\beta$-actin band intensities. Band intensities of room air exposed samples were considered as one arbitrary unit. ${ }^{*} P<0.05$, RA versus hyperoxia.

$6 \mathrm{~h}$, and the levels remained high up to $12 \mathrm{~h}$ (3.6-fold and 5.8fold increases for GCLC and NQO1, resp.) (Figure 2(a)). In contrast, a significant increase in $H M O X 1$ mRNA expression was noticed during the acute phase as early as $3 \mathrm{~h}$ (3.3-fold), and its expression remained high (12.1-fold) up to $12 \mathrm{~h}$. To verify that the changes in mRNA expression also occurred at the protein level, we performed western blot analyses using anti-HMOX1, -GCLC, and -NQO1 antibodies on total protein extracts prepared from cells exposed to hyperoxia or normoxia. In agreement with the RT-PCR data, western blot analyses showed an increased expression of these genes (Figure 2(b)). HMOX1 expression was increased by 1.8-, $1.8-$, and 1.9 -fold at $3 \mathrm{~h}, 6 \mathrm{~h}$, and $12 \mathrm{~h}$, respectively, when compared to the room air control group. Likewise, NQO1 

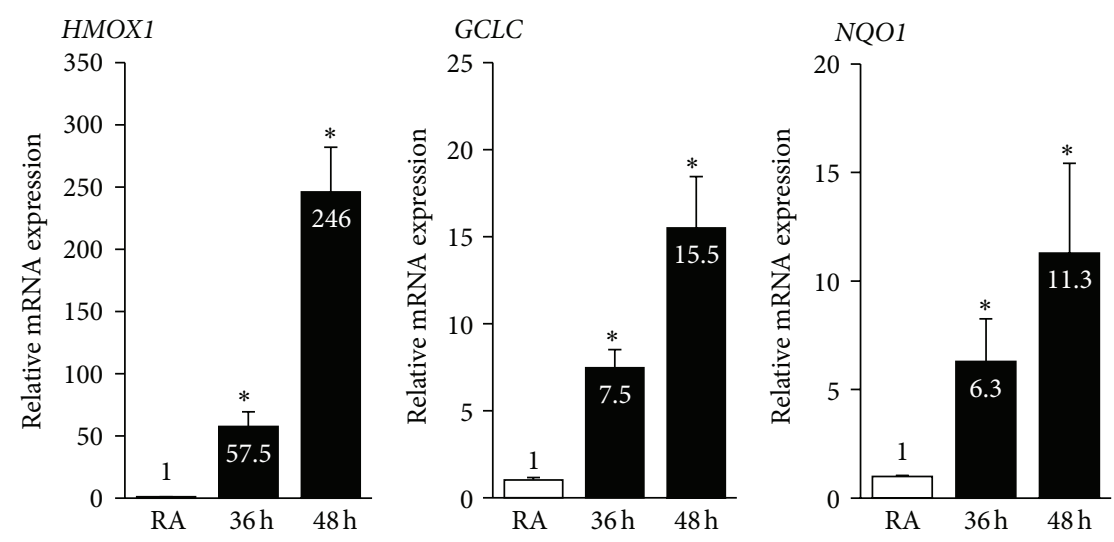

(a)
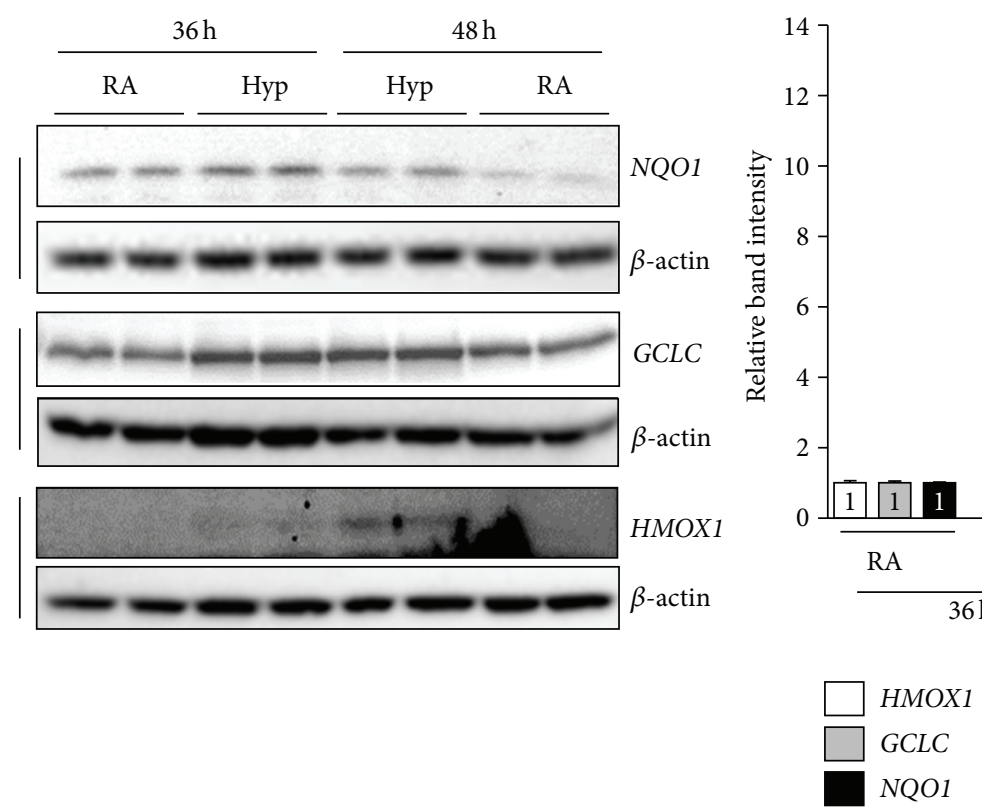

(b)

FIGURE 3: The effects of chronic hyperoxia on NRF2 target gene expression in AECs. Cells were exposed to either room air or hyperoxia for 36 or $48 \mathrm{~h}$ and then harvested for total RNA and protein. (a) HMOX1, GCLC, and NQO mRNA expression. The values represent the mean \pm SD of four independent experiments $(n=6) .{ }^{*} P<0.05$, RA versus hyperoxia. (b) Western blot analysis of whole-cell lysates using anti-HMOX1, anti-NQO1, or anti-GCLC antibodies. Membranes were stripped and reprobed with $\beta$-actin. Graph represents the relative band intensities of HMOX1, NQO, or GCLC, as quantified in Figure 2. Values represent the mean \pm SD of four independent experiments $(n=4)$. ${ }^{*} P<0.05$, RA versus hyperoxia.

expression was increased by 1.7 -fold and 2.3 -fold at $3 \mathrm{~h}$ and $6 \mathrm{~h}$, respectively. No increase was found at the 12 -h time point. In the case of GCLC, the protein expression was increased by 1.4 -fold at the 12-h time point only.

We next analyzed the expression levels of these genes in cells exposed to chronic hyperoxia in order to determine whether their lack of induction by NRF2 could be attributed to cell death. Intriguingly, we found increased levels of HMOX1 (57.5-fold), GCLC (7.5-fold), and NQO1 (6.3-fold)
mRNA expression in cells exposed to chronic hyperoxia $(36 \mathrm{~h})$ when compared to those exposed to room air (Figure 3(a)). The induction of HMOX1 (246-fold), GCLC (15.5-fold), and NQO1 (11.3-fold) mRNA expression remained high up to $48 \mathrm{~h}$. The results of the western blot analyses were correlated with a significantly increased expression of HMOX1 (2.39-fold at $36 \mathrm{~h}$ and 8.34-fold at $48 \mathrm{~h}$ ), GCLC (1.37fold at $36 \mathrm{~h}$ and 1.92 -fold at $48 \mathrm{~h}$ ) and NQO1 (1.57-fold at $36 \mathrm{~h}$ and 2.57-fold at $48 \mathrm{~h}$ ) over the corresponding room air control 

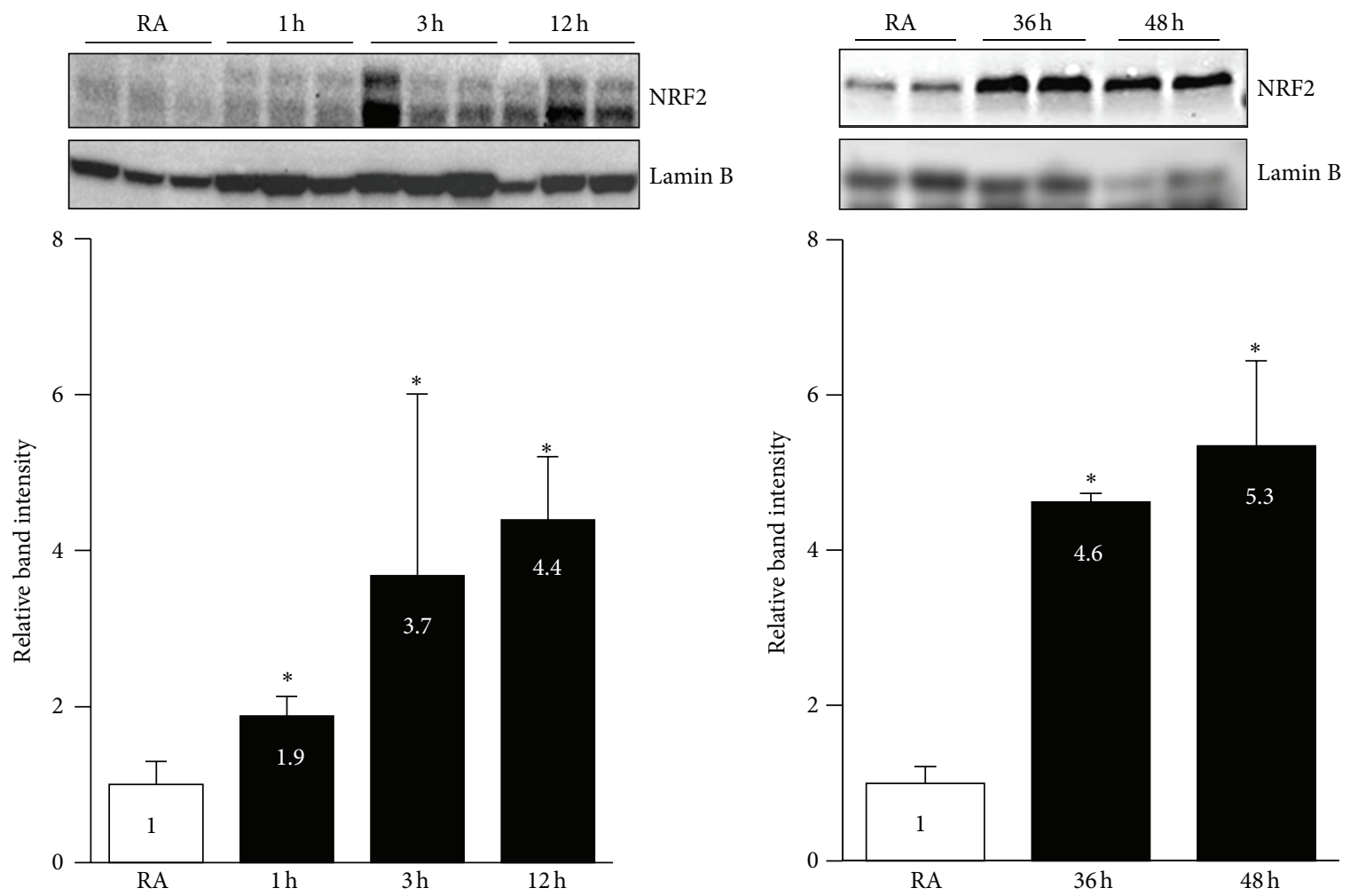

(a)

(b)

FIGURE 4: The effects of acute and chronic hyperoxia on nuclear NRF2 levels. Cells were exposed to room air (RA) or hyperoxia for indicated time points and nuclear extracts were prepared. Equal amount of protein $(\sim 15 \mu \mathrm{g})$ was separated on SDS-PAGE and probed with anti-NRF2 antibody. Membrane was stripped and re-probed with anti-lamin B antibody, as loading control. (a). Nuclear NRF2 levels in cells exposed to hyperoxia for 1 to $12 \mathrm{~h}$. (b) Nuclear NRF2 levels in cells exposed to hyperoxia for $36 \mathrm{~h}$ or $48 \mathrm{~h}$. Graph represents the relative NRF2 band intensity of three independent experiments $\pm \mathrm{SD}(n=3)$. The band intensities of NRF2 were quantified using Image J software and normalized with their respective lamin B band intensities. NRF2 band intensities of room air-exposed samples considered as one arbitrary unit.

groups (Figure 3(b)), but the levels of each protein were not reflected by a corresponding $\mathrm{mRNA}$ abundance.

In order to examine the effects of acute and chronic hyperoxia on NRF2 nuclear accumulation, we exposed AECs to hyperoxia then prepared nuclear extracts and performed western blotting using an anti-NRF2 antibody. Hyperoxia increased the levels of nuclear NRF2 (Figure 4(a)) as early as $1 \mathrm{~h}$ (1.9-fold) after exposure, and the levels remained higher than those of the corresponding room air control group at $3 \mathrm{~h}$ (3.7-fold) and up to $12 \mathrm{~h}$ (4.4-fold). In response to chronic hyperoxia, NRF2 nuclear accumulation was higher at $36 \mathrm{~h}$ (4.6-fold) and $48 \mathrm{~h}$ (5.3-fold) than to room air (Figure 4(b)). These results demonstrate that NRF2 accumulates in the nucleus in response to chronic hyperoxia in a manner comparable to that observed in cells exposed to acute hyperoxia.

To determine whether the increased levels of HMOX1 and NQO1 expression are due to NRF2 binding, we performed ChIP assays analyzing the recruitment of NRF2 to endogenous HMOX1 and NQO1 promoters in cells exposed to acute and chronic hyperoxia. We used gene-specific primers flanking space the critical AREs in each case (Figure 5(a)). These experiments revealed the recruitment of NRF2 to the HMOX1 promoter as early as $3 \mathrm{~h}$; the levels returned to baseline at $6 \mathrm{~h}$ during acute hyperoxia (Figure 5(b), left panel). NRF2 binding to the NQO1 promoter was very low or undetectable under conditions of room air, and it rapidly increased as early as $3 \mathrm{~h}$ (13.5-fold) but returned to basal levels at $6 \mathrm{~h}$ (Figure 5(b), right panel). However, the binding of NRF2 to the NQO1 promoter rose again at $12 \mathrm{~h}$ of hyperoxia (22.4-fold) (Figure 5(b), left panel). An increased enrichment of NRF2 at the NQO1 promoter at the $12 \mathrm{~h}$ time point was also reflected in higher mRNA levels, but western blot analysis revealed no increase in NQO1 protein expression at the $12 \mathrm{~h}$ time point, perhaps because of a lag in mRNA translation.

During chronic hyperoxia, we found that the binding of NRF2 to the HMOX1 enhancer was significantly higher at $36 \mathrm{~h}$ (1.8-fold) and $48 \mathrm{~h}$ (2.4-fold) than in cells exposed to room air (Figure 5(c), left panel). Likewise, during chronic hyperoxia, the binding of NRF2 to the NQO1 promoter, although not higher at the $36 \mathrm{~h}$ time point, was significantly higher at $48 \mathrm{~h}$ than in cells exposed to room air (Figure 5(c), right panel). However, the level of NRF2 enrichment at the NQO1 promoter was considerably lower than in cells exposed to acute hyperoxia (Figure 5(b), right panel). 

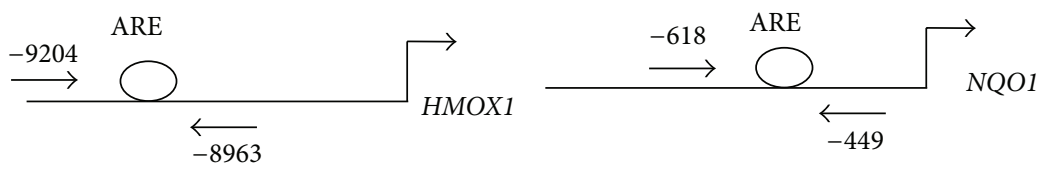

(a)
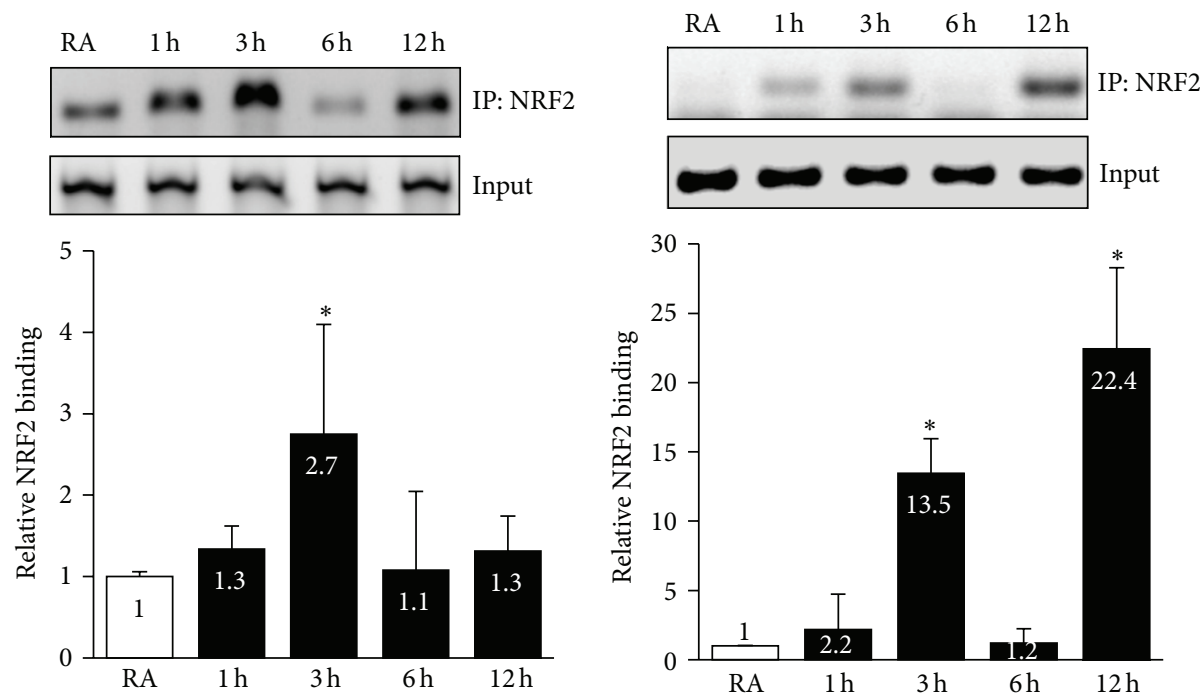

(b)
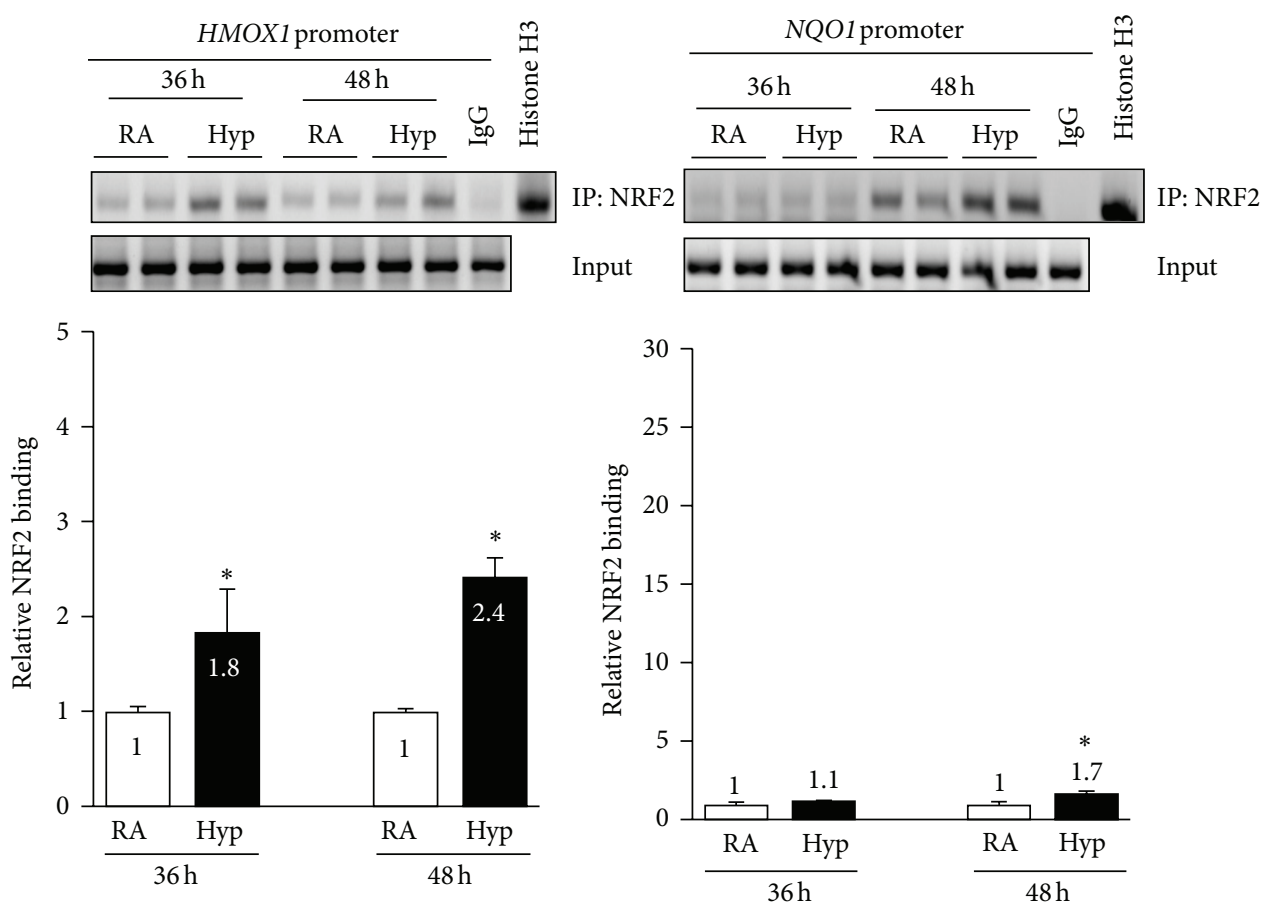

(c)

FIGURE 5: The effects of acute and chronic hyperoxia on the binding of NRF2 to HMOX1 and NQO1 promoters. Cells were exposed to room air or hyperoxia for 1 to $12 \mathrm{~h}$ or for 36 to $48 \mathrm{~h}$; chromatin was cross-linked and immunoprecipitated with IgG or anti-NRF2 antibodies, and DNA was amplified using gene specific primers. (a) Scheme showing the positions of the ARE sites, forward and reverse primers of HMOX1 and NQO1 promoters used in ChIP assays. (b) NRF2 binding to the HMOX1 and NQO1 promoters in cells exposed to acute hyperoxia (1-12 h). (c) NRF2 binding to the HMOX1 and NQO1 promoters in cells exposed to chronic hyperoxia ( $36 \mathrm{~h}$ or $48 \mathrm{~h}$ ). PCR products were analyzed on $2 \%$ agarose gel. Band intensities were quantified with Image J software. Input DNA was used as a control. Graph represents mean \pm SD of five independent experiments $(n=5)$. Fold increase was calculated over their respective room air controls ${ }^{*} P<0.05$, RA versus hyperoxia. 


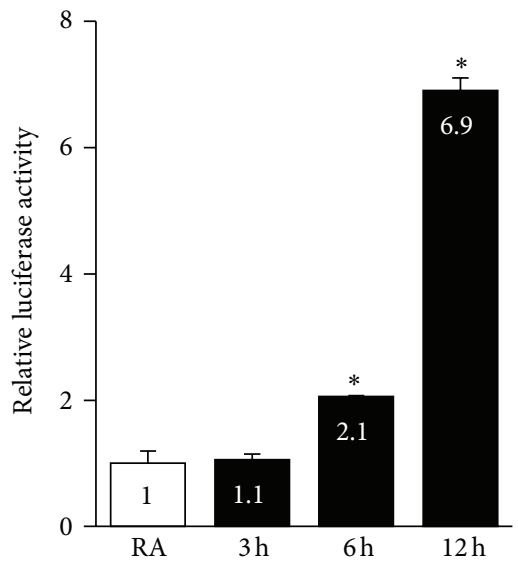

(a)

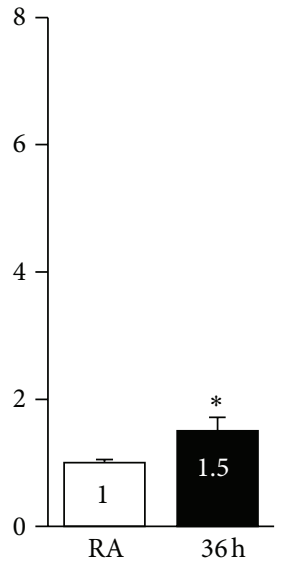

(b)

FIGURE 6: NQO1 promoter activity in AECs exposed to hyperoxia acutely and chronically. To determine the effects of hyperoxia on NQO1 promoter activity, luciferase reporter construct bearing NQO1 promoter (100 ng) and pRL-TK coding for the Renilla luciferase were transiently transfected into AECs, exposed to hyperoxia or room air, and luciferase activity was analyzed using dual luciferase assay kit. The promoter activity of AECs exposed to room air was set as on unit. Values represent the average of 3 independent experiments done in triplicate $(n=9)$.

We next determined the transcriptional activity of the NQO1 promoter in cells exposed to acute and chronic hyperoxia. Cells were transiently transfected with the NQO1-Luc reporter construct and then exposed to hyperoxia. As shown in Figure 6, hyperoxia enhanced NQO1-Luc expression by 2.1- and 6.9-fold at $6 \mathrm{~h}$ and $12 \mathrm{~h}$ of exposure (Figure $6(\mathrm{a})$ ), respectively, when compared to room air controls. We found that the Luc activity was also significantly higher (1.5-fold) in cells exposed to chronic hyperoxia for $36 \mathrm{~h}$ than in the corresponding room air control group (Figure 6(b)); this result is comparable to the 2.1-fold increase found in cells exposed to hyperoxia for $6 \mathrm{~h}$. However, the magnitude of the promoter inducibility was considerably lower than the 6.9fold increase observed in cells exposed to hyperoxia for $12 \mathrm{~h}$.

\section{Discussion}

Exposure to hyperoxia for prolonged periods (chronic exposure) is known to induce oxidative stress, mainly as a result of a redox imbalance caused by excessive accumulation of reactive oxygen species, which initially causes cellular damage and ultimately cell death [23]. NRF2-induced expression of antioxidative and cytoprotective genes is crucial to maintaining redox homeostasis during exposure to toxicants and injurious insults. We have previously shown that mice lacking Nrf2 are highly susceptible to hyperoxia-induced lung injury and lung epithelial cell death in vivo and in vitro $[8,14]$, suggesting that prolonged exposure to hyperoxia promotes lung epithelial cell injury and death by impairing NRF2 activation and subsequently inhibiting its induction of downstream target genes. However, in the present study, we demonstrate that the enhanced expression levels of putative NRF2 target genes in lung epithelial cells exposed to chronic hyperoxia are of a higher magnitude than those observed under acute hyperoxia. Moreover, we observed that the recruitment of nuclear NRF2 to the promoters of antioxidant genes (e.g., HMOX1 and NQO1) in cells exposed to chronic hyperoxia. Thus, it appears that NRF2-mediated gene expression is not globally or largely compromised, but it induced to mount a cytoprotective response to preserve redox homeostasis, thereby helping to maintain cell survival or preventing lung epithelial cell death during chronic hyperoxia.

NRF2 is mainly localized to the cytoplasm in its native state, and its nuclear accumulation in response to stressful insults is critical for antioxidant gene induction [24, 25]. The nucleocytoplasmic shuttling of NRF2 appears to vary according to the inducer and/or cell type and is regulated by multiple complex mechanisms $[24,25]$. For example, various protein kinases, such as PKC [26, 27], ERK1/2 [28], and AKT [29], activated by pro-oxidant exposure, are also known to facilitate and enhance the accumulation of NRF2 in the nucleus. After the signal-induced dissociation from its cytoplasmic inhibitor Keapl, importins facilitate the nuclear translocation of NRF2 [30]. Phosphorylation of NRF2 in the nucleus promotes its nuclear exclusion and subsequent Keap1-mediated degradation [31, 32]. Thus, deregulation of NRF2 nuclear accumulation following chronic stressful stimuli, such as hyperoxia, is generally connected with cellular injury and death. However, our present results indicate that this is not the case. We found higher levels of NRF2 in the nucleus of cells during chronic hyperoxia than in room airexposed cells, and the levels were comparable to those of 
cells exposed to acute hyperoxia, suggesting that the various effector pathways that facilitate nuclear accumulation of NRF2 and its DNA binding are functional during conditions of hyperoxia-induced lung epithelial cell death.

NRF2 alone is insufficient to bind to the ARE. Its heterodimerization with other b-ZIP transcription factors, such as JUN and the small MAF family of proteins, is also required [33-36]. The magnitude and duration of the antioxidant gene expression can be dictated by both cooperative and combinatorial interactions that occur between NRF2 and the MAF/JUN family of proteins. Thus, the impairment of NRF2 binding to the DNA might affect its transactivational activity, despite elevated levels of NRF2 in the nucleus. Because the levels of NRF2-dependent target gene expression are almost higher under chronic hyperoxia than during exposure to acute hyperoxia, it appears that hyperoxia does not alter these interactions or diminish the lung antioxidant capacity, leading to a dysfunctional cellular response. Members of the Jun family of proteins, c-Jun and Jun-D, can dimerize with $\mathrm{Nrf2}$ and upregulate antioxidant gene expression $[37,38]$. For example, mouse embryonic fibroblasts lacking c-Jun or Jun$D$ demonstrate decreased levels of antioxidant enzymes and enhanced oxidative stress [33-36]. Likewise, c-Myc upregulates the expression of cytoprotective genes in response to stressful stimuli [39]. Thus, it is possible that these proteins act in a cooperative or synergistic manner with NRF2 to potentiate ARE-mediated gene transcription during chronic hyperoxia.

We have previously reported the binding of Nrf2 to AREs in murine alveolar type-II like epithelial cells following acute hyperoxia $[14,28]$. In the present study, ChIP assays revealed the binding of NRF2 to its target gene promoters (NQO1 and HMOX1) in cells exposed to chronic hyperoxia ( $48 \mathrm{~h})$, suggesting that chronic hyperoxia does not compromise NRF2 binding to antioxidant promoters. Although the magnitude of the NRF2 binding at the HMOX1 promoter was similar under acute (at $3 \mathrm{~h}$ ) and chronic (at $36 \mathrm{~h}$ and $48 \mathrm{~h}$ ) hyperoxic conditions (Figure 5), the enrichment of NRF2 at the NQO1 promoter appeared to be variable and biphasic in response to hyperoxia. There was a 13 -fold increase in the binding of NRF2 to the NQO1 promoter at $3 \mathrm{~h}$, and the binding returned to basal levels at $6 \mathrm{~h}$ after hyperoxia. However, the NRF2 binding increased significantly to greater levels at $12 \mathrm{~h}$ than at $3 \mathrm{~h}$ after hyperoxia. During chronic hyperoxia, a significant increase in NRF2 binding at the NQO1 promoter was detected at $48 \mathrm{~h}$, but not at $36 \mathrm{~h}$, when compared to room air controls. It is possible that the association of NRF2 with its partners is dynamic or that its negative regulators, such as BACH1 [40] and Fra-1 [41], limit the availability of NRF2 or its partners to form complexes with NRF2, making it differentially bind to the AREs in a gene-promoter contextdependent manner during acute and chronic hyperoxia. The relevance and mechanisms of such differential NRF2 binding to the NQO1 promoter during hyperoxia-induced cell death warrants a separate investigation.

It is noteworthy that the lower NRF2 binding at the endogenous NQO1 promoter was reflected in diminished promoter activation by chronic hyperoxia in our transient transfection assays; however, NQO1 mRNA expression levels in cells exposed to chronic hyperoxia were nearly comparable to those observed in cells exposed to acute hyperoxia. We assume that the posttranscriptional regulation of NQO1 explains the discordance between diminished promoter activity and increased mRNA expression of NQO1 in chronic hyperoxia. It should also be noted that reporter analyses utilize a short fragment of the promoter, unlike the native gene promoter, and this difference may also explain some of the differences. Also, we would like to point out the lack of a direct correlation between mRNA and protein expression. For example, the increased protein abundance of $H M O X 1$ and other genes analyzed by western blot analysis was $\sim 10$-fold less than the corresponding mRNA expression levels in cells exposed to either acute or chronic hyperoxia. It is unclear whether this result reflects error and noise in the real-time PCR and immunoblot analysis and/or variations in protein synthesis and degradation [42].

Previously, it has been shown that the exposure to oxidants (such as high doses of $\mathrm{H}_{2} \mathrm{O}_{2}$ ) leads to decreased NRF2 levels and a consequent suppression of the antioxidant response pathway, culminating in cellular injury and death $[43,44]$. However, we found that nuclear NRF2 protein levels in cells exposed to chronic hyperoxia are not reduced when compared to room air-exposed cells or to cells exposed to acute hyperoxia (Figure 4), ruling out such a possibility. The ability of hyperoxia to induce cell death despite the presence of high levels of antioxidant gene expression is somewhat surprising. It is important to note that we have only analyzed the expression of a subset of the NRF2-target genes (GCLC, HMOX1, and NQO1) (data not shown for TRX1 and GCLM) that are markedly induced during chronic hyperoxia. Previously, by global gene expression profiling and primary lung type alveolar II epithelial cultures from Nrf2null and wild-type mice, we have shown that Nrf2 regulates the expression of several genes involved in antioxidative and cytoprotective responses as well as cell proliferation and survival [14, 45]. Global mapping ChIP-binding assays and mRNA expression profiling in Keap1-null or Nrf2-null mouse embryonic fibroblasts revealed that $\mathrm{Nrf2}$ binds and regulates the expression of $\sim 500$ genes involved in cell proliferation and stress response [46]. It is possible that some of these gene products that dampen the initiation and execution of cell death pathways are not being induced by NRF2 during chronic hyperoxia, despite its nuclear presence; we cannot rule out this possibility. Recently, Taguchi et al. have demonstrated that an increased level of NRF2 accumulation promotes liver damage in autophagy-deficient mice [47]. Whether high levels of nuclear NRF2 have any role in mediating cellular injury during chronic hyperoxic setting remains to be investigated.

In summary, we have demonstrated that both NRF2 nuclear enrichment and upregulation of antioxidative gene expression occur in cells exposed to chronic hyperoxia. ChIP assays revealed that the magnitude of the NRF2 binding at the antioxidant gene promoters is dynamic, variable, and biphasic in response to hyperoxia exposure, suggesting that NRF2mediated signaling is not globally or largely compromised. 
Rather, it continues to be functional during chronic hyperoxia that causes the death of lung epithelial cells.

\section{Conflict of Interests}

All the authors declare no conflict of interests.

\section{Acknowledgments}

This work was funded by the National Institute of Health Grants HL66109, ES11863 and ES18998 (to Sekhar P. Reddy), and CA78282 and CA105005 (to Dhananjaya V. Kalvakolanu).

\section{References}

[1] Y. S. Ho, R. Vincent, M. S. Dey, J. W. Slot, and J. D. Crapo, "Transgenic models for the study of lung antioxidant defense: enhanced manganese-containing superoxide dismutase activity gives partial protection to b6c3 hybrid mice exposed to hyperoxia," American Journal of Respiratory Cell and Molecular Biology, vol. 18, no. 4, pp. 538-547, 1998.

[2] P. J. Lee and A. M. K. Choi, "Pathways of cell signaling in hyperoxia," Free Radical Biology and Medicine, vol. 35, no. 4, pp. 341-350, 2003.

[3] O. D. Saugstad, "Bronchopulmonary dysplasia-oxidative stress and antioxidants," Seminars in Neonatology, vol. 8, no. 1, pp. 3949, 2003.

[4] I. Fridovich, "Oxygen toxicity: a radical explanation," Journal of Experimental Biology, vol. 201, no. 8, pp. 1203-1209, 1998.

[5] B. Halliwell, J. M. C. Gutteridge, and C. E. Cross, "Free radicals, antioxidants, and human disease: where are we now?" Journal of Laboratory and Clinical Medicine, vol. 119, no. 6, pp. 598-620, 1992.

[6] W. MacNee and I. Rahman, "Is oxidative stress central to the pathogenesis of chronic obstructive pulmonary disease?" Trends in Molecular Medicine, vol. 7, no. 2, pp. 55-62, 2000.

[7] J. D. Crapo, "Morphologic changes in pulmonary oxygen toxicity," Annual Review of Physiology, vol. 48, pp. 721-731, 1986.

[8] H. Y. Cho, A. E. Jedlicka, S. P. M. Reddy et al., "Role of NRF2 in protection against hyperoxic lung injury in mice," American Journal of Respiratory Cell and Molecular Biology, vol. 26, no. 2, pp. 175-182, 2002.

[9] H. Y. Cho, A. E. Jedlicka, S. P. M. Reddy, L. Y. Zhang, T. W. Kensler, and S. R. Kleeberger, "Linkage analysis of susceptibility to hyperoxia Nrf2 is a candidate gene," American Journal of Respiratory Cell and Molecular Biology, vol. 26, no. 1, pp. 42-51, 2002.

[10] N. M. Reddy, V. Suryanarayana, D. V. Kalvakolanu et al., "Innate immunity against bacterial infection following hyperoxia exposure is impaired in NRF2-deficient mice," Journal of Immunology, vol. 183, no. 7, pp. 4601-4608, 2009.

[11] H. Y. Cho, B. van Houten, X. Wang et al., “Targeted deletion of nrf2 impairs lung development and oxidant injury in neonatal mice," Antioxidants and Redox Signaling, vol. 17, no. 8, pp. 10661082, 2012.

[12] S. McGrath-Morrow, T. Lauer, M. Yee et al., "Nrf2 increases survival and attenuates alveolar growth inhibition in neonatal mice exposed to hyperoxia," American Journal of Physiology, vol. 296, no. 4, pp. L565-L573, 2009.
[13] N. M. Reddy, S. R. Kleeberger, H. Y. Cho et al., "Deficiency in Nrf2 GSH signaling impairs type II cell growth and enhances sensitivity to oxidants," American Journal of Respiratory Cell and Molecular Biology, vol. 37, no. 1, pp. 3-8, 2007.

[14] S. Papaiahgari, S. R. Kleeberger, H. Y. Cho, D. V. Kalvakolanu, and S. P. Reddy, "NADPH oxidase and ERK signaling regulates hyperoxia-induced Nrf2-ARE transcriptional response in pulmonary epithelial cells," Journal of Biological Chemistry, vol. 279, no. 40, pp. 42302-42312, 2004.

[15] N. Morito, K. Yoh, K. Itoh et al., "Nrf2 regulates the sensitivity of death receptor signals by affecting intracellular glutathione levels," Oncogene, vol. 22, no. 58, pp. 9275-9281, 2003.

[16] S. B. Cullinan, D. Zhang, M. Hannink, E. Arvisais, R. J. Kaufman, and J. A. Diehl, "Nrf2 is a direct PERK substrate and effector of PERK-dependent cell survival," Molecular and Cellular Biology, vol. 23, no. 20, pp. 7198-7209, 2003.

[17] C. Q. Piao, L. Liu, Y. L. Zhao, A. S. Balajee, M. Suzuki, and T. K. Hei, "Immortalization of human small airway epithelial cells by ectopic expression of telomerase," Carcinogenesis, vol. 26, no. 4, pp. 725-731, 2005.

[18] J. D. Moehlenkamp and J. A. Johnson, "Activation of antioxidant/electrophile-responsive elements in IMR-32 human neuroblastoma cells," Archives of Biochemistry and Biophysics, vol. 363, no. 1, pp. 98-106, 1999.

[19] A. Singh, V. Misra, R. K. Thimmulappa et al., "Dysfunctional KEAP1-NRF2 interaction in non-small-cell lung cancer," PLoS Medicine, vol. 3, no. 10, pp. 1865-1876, 2006.

[20] B. Padmanabhan, K. I. Tong, T. Ohta et al., "Structural basis for defects of Keapl activity provoked by its point mutations in lung cancer," Molecular Cell, vol. 21, no. 5, pp. 689-700, 2006.

[21] T. Suzuki, J. Maher, and M. Yamamoto, "Select heterozygous Keapl mutations have a dominant-negative effect on wild-type Keap1 in vivo," Cancer Research, vol. 71, no. 5, pp. 1700-1709, 2011.

[22] T. W. Kensler, N. Wakabayashi, and S. Biswal, "Cell survival responses to environmental stresses via the Keap1-Nrf2-ARE pathway," Annual Review of Pharmacology and Toxicology, vol. 47, pp. 89-116, 2007.

[23] C. Barazzone, S. Horowitz, Y. R. Donati, I. Rodriguez, and P. F. Piguet, "Oxygen toxicity in mouse lung: pathways to cell death," American Journal of Respiratory Cell and Molecular Biology, vol. 19, no. 4, pp. 573-581, 1998.

[24] M. Kobayashi and M. Yamamoto, "Molecular mechanisms activating the Nrf2-Keap1 pathway of antioxidant gene regulation," Antioxidants and Redox Signaling, vol. 7, no. 3-4, pp. 385-394, 2005.

[25] H. Y. Cho, S. P. Reddy, and S. R. Kleeberger, "Nrf2 defends the lung from oxidative stress," Antioxidants \& Redox Signaling, vol. 8, no. 1-2, pp. 76-87, 2006, Review.

[26] H. C. Huang, T. Nguyen, and C. B. Pickett, "Regulation of the antioxidant response element by protein kinase C-mediated phosphorylation of NF-E2-related factor 2," Proceedings of the National Academy of Sciences of the United States of America, vol. 97, no. 23, pp. 12475-12480, 2000.

[27] H. C. Huang, T. Nguyen, and C. B. Pickett, "Phosphorylation of Nrf2 at Ser-40 by protein kinase C regulates antioxidant response element-mediated transcription," Journal of Biological Chemistry, vol. 277, no. 45, pp. 42769-42774, 2002.

[28] S. Papaiahgari, Q. Zhang, S. R. Kleeberger, H. Y. Cho, and S. P. Reddy, "Hyperoxia stimulates an Nrf2-ARE transcriptional response via ROS-EGFR-P13K-Akt/ERK MAP kinase signaling 
in pulmonary epithelial cells," Antioxidants and Redox Signaling, vol. 8, no. 1-2, pp. 43-52, 2006.

[29] J. H. Lim, K. M. Kim, S. W. Kim, O. Hwang, and H. J. Choi, "Bromocriptine activates NQO1 via Nrf2-PI3K/Akt signaling: novel cytoprotective mechanism against oxidative damage," Pharmacological Research, vol. 57, no. 5, pp. 325-331, 2008.

[30] M. Theodore, Y. Kawai, J. Yang et al., "Multiple nuclear localization signals function in the nuclear import of the transcription factor Nrf2," Journal of Biological Chemistry, vol. 283, no. 14, pp. 8984-8994, 2008.

[31] J. W. Kaspar and A. K. Jaiswal, "Antioxidant-induced phosphorylation of tyrosine 486 leads to rapid nuclear export of Bach1 that allows Nrf2 to bind to the antioxidant response element and activate defensive gene expression," Journal of Biological Chemistry, vol. 285, no. 1, pp. 153-162, 2010.

[32] R. N. Karapetian, A. G. Evstafieva, I. S. Abaeva et al., "Nuclear oncoprotein prothymosin $\alpha$ is a partner of Keap1: implications for expression of oxidative stress-protecting genes," Molecular and Cellular Biology, vol. 25, no. 3, pp. 1089-1099, 2005.

[33] D. Gerald, E. Berra, Y. M. Frapart et al., "JunD reduces tumor angiogenesis by protecting cells from oxidative stress," Cell, vol. 118, no. 6, pp. 781-794, 2004.

[34] A. MacLaren, E. J. Black, W. Clark, and D. A. F. Gillespie, "CJun-deficient cells undergo premature senescence as a result of spontaneous DNA damage accumulation," Molecular and Cellular Biology, vol. 24, no. 20, pp. 9006-9018, 2004.

[35] A. Meixner, F. Karreth, L. Kenner, J. M. Penninger, and E. F. Wagner, "Jun and JunD-dependent functions in cell proliferation and stress response," Cell Death and Differentiation, vol. 17, no. 9, pp. 1409-1419, 2010.

[36] J. B. Weitzman, L. Fiette, K. Matsuo, and M. Yaniv, "JunD protects cells from p53-dependent senescence and apoptosis," Molecular Cell, vol. 6, no. 5, pp. 1109-1119, 2000.

[37] K. Igarashi, K. Kataoka, K. Itoh, N. Hayashi, M. Nishizawa, and M. Yamamoto, "Regulation of transcription by dimerization of erythroid factor NF-E2 p45 with small Maf proteins," Nature, vol. 367 , no. 6463 , pp. 568-572, 1994.

[38] R. Venugopal and A. K. Jaiswal, "Nrf2 and Nrf1 in association with Jun proteins regulate antioxidant response elementmediated expression and coordinated induction of genes encoding detoxifying enzymes," Oncogene, vol. 17, no. 24, pp. 3145-3156, 1998.

[39] C. V. Dang, K. A. O’Donnell, K. I. Zeller, T. Nguyen, R. C. Osthus, and F. Li, "The c-Myc target gene network," Seminars in Cancer Biology, vol. 16, no. 4, pp. 253-264, 2006.

[40] S. Dhakshinamoorthy, A. K. Jain, D. A. Bloom, and A. K. Jaiswal, "Bach1 competes with Nrf2 leading to negative regulation of the antioxidant response element (ARE)-mediated $\mathrm{NAD}(\mathrm{P}) \mathrm{H}$ :quinone oxidoreductase 1 gene expression and induction in response to antioxidants," Journal of Biological Chemistry, vol. 280, no. 17, pp. 16891-16900, 2005.

[41] M. Vaz, N. Machireddy, A. Irving et al., "Oxidant-induced cell death and Nrf2-dependent antioxidative response are controlled by Fra-1/AP-1," Molecular and Cellular Biology, vol. 32, no. 9, pp. 1694-1709, 2012.

[42] D. Greenbaum, C. Colangelo, K. Williams, and M. Gerstein, "Comparing protein abundance and mRNA expression levels on a genomic scale," Genome Biology, vol. 4, no. 9, article 117, 2003.
[43] J. L. Ning, L. W. Mo, and X. N. Lai, "Low-and high-dose hydrogen peroxide regulation of transcription factor NF-E2related factor 2," Chinese Medical Journal, vol. 123, no. 8, pp. 1063-1069, 2010.

[44] N. F. Villeneuve, Z. Sun, W. Chen, and D. D. Zhang, "Nrf2 and p21 regulate the fine balance between life and death by controlling ROS levels," Cell Cycle, vol. 8, no. 20, pp. 3255-3256, 2009.

[45] N. M. Reddy, S. R. Kleeberger, M. Yamamoto et al., "Genetic dissection of the Nrf2-dependent redox signaling-regulated transcriptional programs of cell proliferation and cytoprotection," Physiological Genomics, vol. 32, no. 1, pp. 74-81, 2007.

[46] D. Malhotra, E. Portales-Casamar, A. Singh et al., "Global mapping of binding sites for Nrf2 identifies novel targets in cell survival response through chip-seq profiling and network analysis," Nucleic Acids Research, vol. 38, no. 17, Article ID gkq212, pp. 5718-5734, 2010.

[47] K. Taguchi, N. Fujikawa, M. Komatsu et al., "Keapl degradation by autophagy for the maintenance of redox homeostasis," Proceedings of the National Academy of Sciences of the United States of America, vol. 109, no. 34, pp. 13561-13566, 2010. 


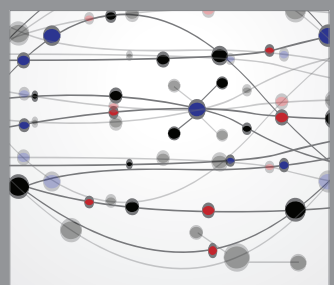

The Scientific World Journal
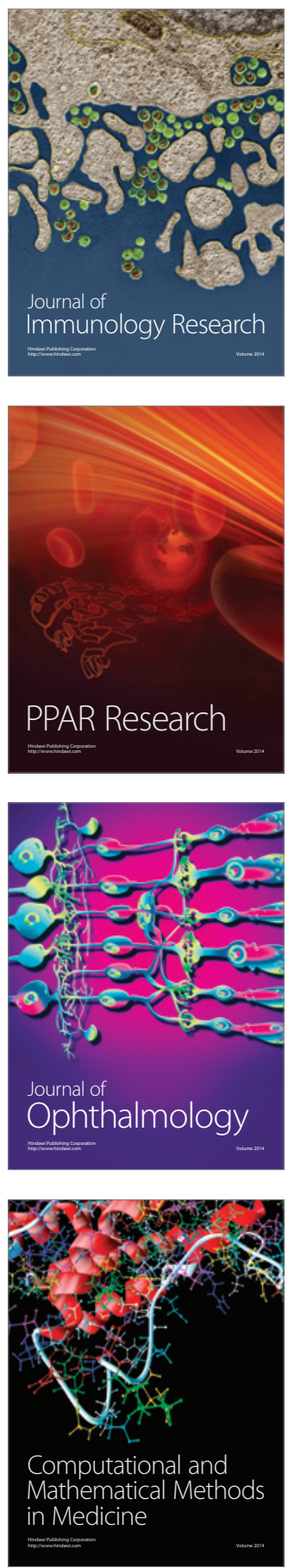

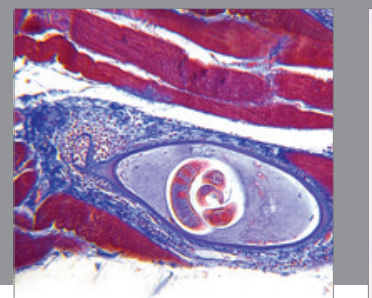

Gastroenterology

Research and Practice
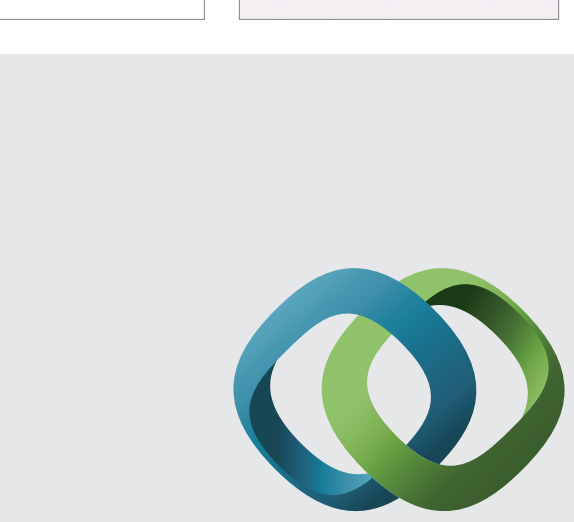

\section{Hindawi}

Submit your manuscripts at

http://www.hindawi.com
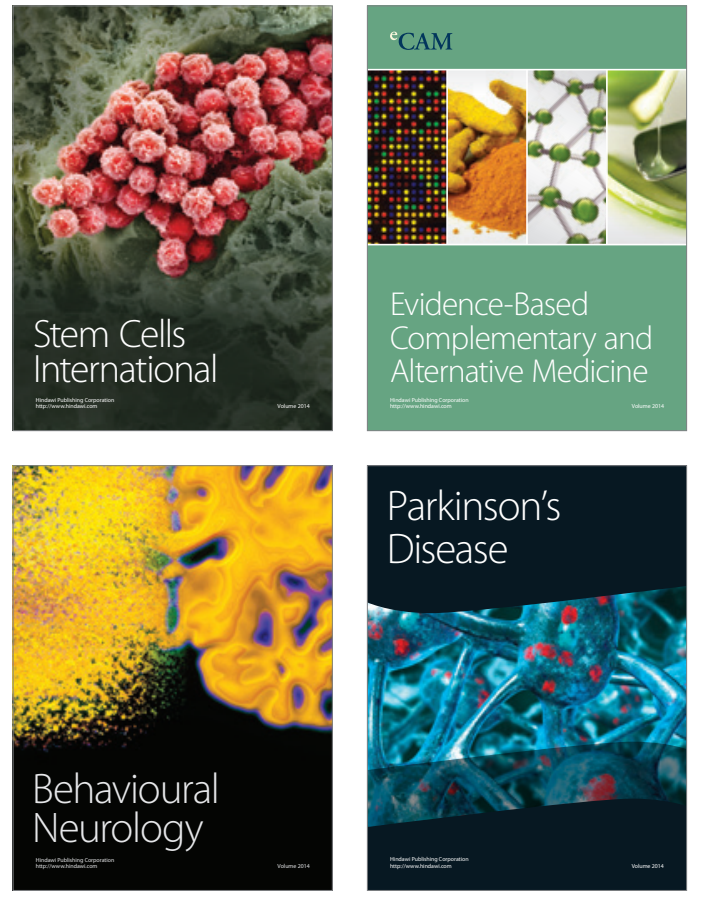
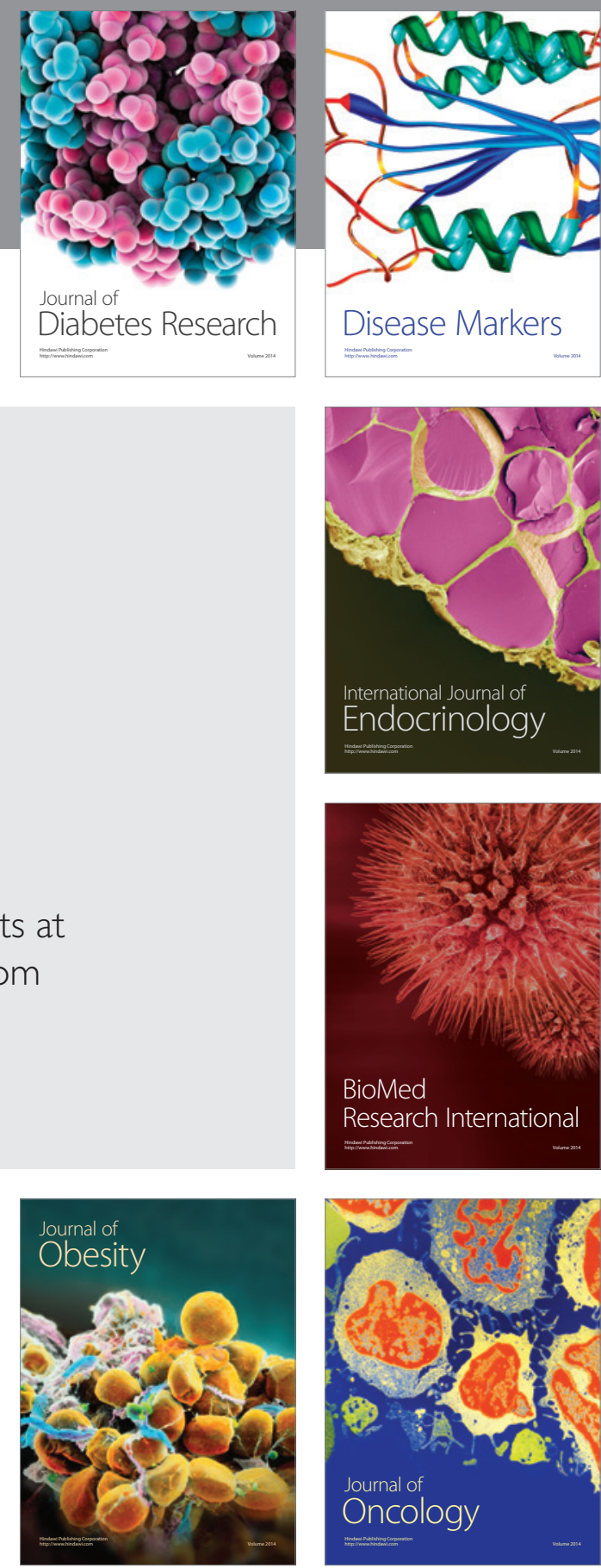

Disease Markers
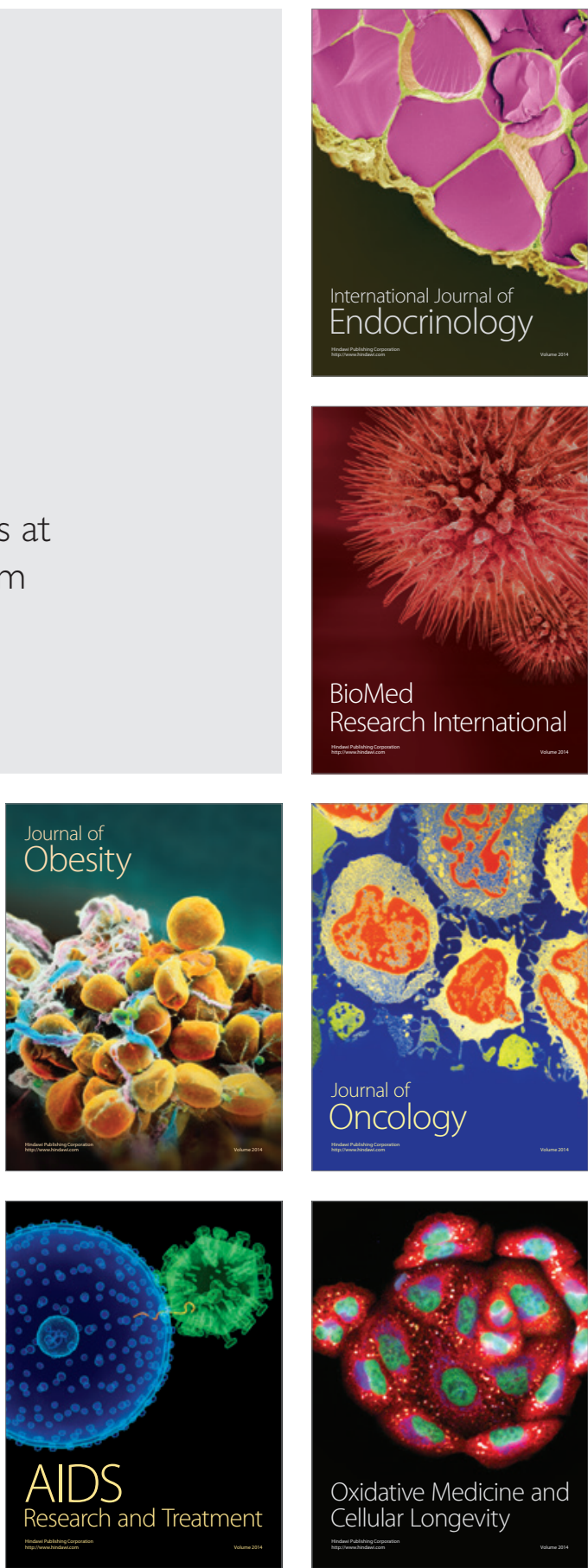